\title{
Manuel Zapata Olivella, poemas inéditos ${ }^{1}$
}

\section{Consagración de Nagó}

¡Acércate Nagó!

Arrodíllate bajo las sombras del baobab

esta noche

en presencia de los Orichas

te consagro.

Nagó navegante

hijo de Jalunga

biznieto de Sassandra

escogido de los Orichas

\section{2}

Semilla que mueres

semilla que renaces

puente de dos mundos te nombré,

entre la casa de los Ancestros que se queda

y la morada extraña a donde llegas

¡Por voluntad de los Ancestros

esta noche te consagro!

\begin{abstract}
Abre los brazos
quédate inmóvil en el ritmo

que la vertical de tu cuerpo

sobre tus brazos abiertos

sea la cruz de Elegba

vida y sombra de nuestro pueblo

en el país desconocido.
\end{abstract}

\footnotetext{
${ }^{1}$ Los poemas de Manuel Zapata Olivella transcriptos en esta sección provienen de Manuel Zapata Olivella's Papers en la Biblioteca Alexander Heard de Vanderbilt University. Para mayor información sobre los mismos, ver el artículo de John Maddox incluido en el dossier de este número de Visitas al patio.
} 
La cruz, símbolo que te nombra

será tu palabra, tu lanza y tu sombra,

Levanta la tenaz del herrero

forjada en las fraguas de Ogún

y crúzala sobre tu lanza cazadora

Elegba Consagra a Nagó el Navegante

¡Acércate Nagó!

Arrodíllate bajo las sombras del baobab.

¡Hijo de Jalunga el navegante

biznieto de Sassandra

escogido de los Orichas

entre la muerte y la vida

entre la ceniza y la esperanza

entre el dolor y la risa

entre la alegría y el llanto

por voluntad de los Ancestros

esta noche te consagro!

\section{2}

con sus generales,

sus tres hermanos

¡Ogún!

¡Ochosí!

¡Ochún!

Danzan sus cabalgaduras

los caballos humanos.

¡Acércate Nagó!

Arrodíllate bajo las sombras del baobab

esta noche

en presencia de los Orichas

te consagro. 


\section{Consagración de Nagó}

Nagó navegante

hijo de Jalunga

biznieto de Sassandra

escogido de los Orichas

\section{1}

Que todo sea paz y reposo cuando yo inicie mi

(largo relato,

la historia de mi nación ultrajada.

¡Acércate Nagó!

Arrodíllate bajo las sombras del baobab.

¡Hijo de Jalunga el navegante

bisnieto de Sassandra

escogido de los Orichas

entre la muerte y la vida

entre la ceniza y la esperanza

entre el dolor y la risa

entre la alegría y el llanto

por voluntad de los Ancestros

esta noche te consagro!

44

“Ngafúa presenta a Nagó el Navegante [sic]",

(Linga incansable

recoge tu voz eco

las preguntas sin respuestas

las voces ahogadas en el río

las palabras perdidas en las cuevas

¡Recoge tu voz eco 
Linga incansable

y dame el ritmo lento de la danza!)

Os presento a Nagó el navegante, biznieto de Sassandra, el Grebo.

Ogún el tallador de los fuegos

escogió entre tótems su modelo:

\section{5}

serpiente burladora de trampas;

movimientos rápidos de ardilla;

coraza de rinoceronte para el pecho;

potente mandíbula, garra de león.

El vaho, los sudores, la saliva

aceitan su resbalosa piel de anguila

para limar, para moler los cepos

de la dentada quijada de la Loba

que en la guarida de las bodegas

tritura la luz, la vida y los huesos.

Las Orichas de los ríos y las ciénagas

amasaron en el vientre de la madre

su rostro húmedo con los dedos

las tristezas, la sonrisa, los deseos.

Puso Ochú bajo la hojarasca de sus cejas

los encendidos tizones de sus ojos

que al abrirlos alumbrarán su rostro

hasta con el brillo de una lágrima.

Desatando los nudos de su lengua

en sus labios dormidos los Ancestros

46

encendieron las palabras

para que entre ekobios desterrados 
los temores borrara con su voz

la esperanza sembrara con su sombra.

Fue Legba el sagrado dibujante

quien trazó la planta de su pie

alargada huella entre dos mundos,

ala ágil de los barcos navegantes

brújula de quillas y abridor de rumbos.

Y para señal de ciegos, mudos y sordos

el símbolo mágico de las dos serpientes

visible, nudosas, marcó sobre hombros.

Escuchemos su memoria relato

lo que vieron sus ojos en dormidos espejos

la luz suelta de los pájaros

los volcanes de ronco trueno,

la raza tribu de los Hombres-Babillas

milenarios sabios de otros mundos

en la América violada por la Loba

cárcel vil, forja de Changó

para templar el Muntu.

\section{9}

Elegba Consagra a Nagó el Navegante

\section{¡Acércate Nagó!}

Arrodíllate bajo las sombras del baobab.

¡Hijo de Jalunga el navegante

biznieto de Sassandra

escogido de los Orichas

entre la muerte y la vida

entre la ceniza y la esperanza

entre el dolor y la risa

entre la alegría y el llanto 
por voluntad de los Ancestros

esta noche te consagro!

Semillas que mueres

semilla que renaces

puente de dos mundos te nombro,

entre la casa de los Ancestros que se queda

y la morada extraña a donde llegas.

100

¡Por voluntad de los Ancestros

esta noche te consagro!

Abre los brazos

quédate inmóvil en el ritmo

que la vertical de tu cuerpo

sobre tus brazos abiertos

sea la cruz de Elegba

vida y sombra de nuestro pueblo

en el país desconocido.

La cruz, símbolo que te nombra

será tu palabra, tu lanza y tu sombra.

Levanta la tenaza del herrero

forjada en las fraguas de Ogún

y crúzala sobre tu lanza cazadora

\section{1}

la ponderosa lanza de agudo rostro regalo de Ochosí.

Serán tus armas y escudos

sobre cadenas y amos vencedoras. 
Hijo de Jalunga el Grebo dos serpientes mordiéndose las colas identificarán tu presencia en la tiránica tierra del exilio. Por voluntad de Elegba serás su símbolo y mensajero capitán de las revueltas tribus su combatiente compañero.

Toma tu lanza

a tus hermanos hará fuerte.

Cierra la boca, los oídos oigan tu pensamiento.

Escucha la palabra de Elegba

en el ritmo invisible de las cosas

solo oyéndolo conocerás el aliento

latente de la vida

que se agita

\section{2}

que se esconde

en el polvo, los mares y el aire.

Tu lengua oiga los sabores

en las aguas diluidas

en los poros y en el grano

en los jugos de las flores

y en la sal de las piedras.

Que tu piel parche de tambor sea sensible a la lluvia percutora al minúsculo respiro de la gota y a la palabra trueno de la nube.

La telaraña de tu oído

capture el vuelo de la luciérnaga 
y el sueño de los huevos en su nido.

Solo viendo los invisibles sonidos

descubrirás los mensajes escondidos.

Tu corazón

\section{3}

permanente llamarada

alegrará la rebelde sonrisa del ahorcado

y la lágrima de la madre

que deje embarazada.

En el grito de su hijo

estarás en su sombra

cubriéndole la huella.

¡Eía Nagó hijo de Jalunga

biznieto de Sassandra!

Caminante sin reposo

los Orichas te dejan mirar

la cristalina fuente del futuro

el porvenir que corre hacia tu encuentro

desde el más remoto confín hasta tus ojos.

Habitante en otros cuerpos

sembrarás el sol en sus noches

sabiduría en las palabras

fuego en la ceniza

vida en la muerte

risa en el dolor

\section{4}

risa en el dolor

belleza en la fealdad

y constancia en el rencor. 
Por un camino cerrado

abrirás siete puertas.

Libre, al hijo que te maten

le nacerán siete cabezas.

Herrero de la vida

bala de la muerte

vencerás la angustia.

Mágico cuerpo de serpiente

cada anillo de tu cola cascabel viviente.

Protegido de [Tachado: Elegba. Escrito a mano: Changó]

caminante sin retorno

presente memoria

pasada experiencia

vivo recuerdo de los sabios

verbo creador

la vida sale

al golpe de tus labios.

\section{5}

Gran clarividente

recorrerás sentado los caminos del tiempo

el pasado viviente

el mañana ayer

las olvidadas hazañas de los muertos

los pasos de los nietos por nacer

los días aún no fecundados por la luz.

Tus ojos abiertos espejos del pasado

espejos del futuro tus ojos cerrados.

Así naces esta noche cargado de presagios

inmortal por voluntad de los Orichas

en cada parto revivirás

la muerte de otras vidas. 
¡Esta noche te consagro!

¡Marcha firme!

¡Marcha orgulloso!

¡Esta noche matas tu pasado

esta noche nace tu futuro!

\section{8}

\section{Presentación de Nagó a Bandama o La alargada huella entre dos mundos}

(Linga incansable

recoge tu voz eco

las preguntas sin respuestas

las voces ahogadas en el río

Las palabras perdidas en las cuevas sin salida

recoge tu voz eco

linga incansable

Y dame el ritmo lento de la danza.)

Os presentó a Nagó el navegante, [Tachado: hijo] biznieto de Sassandra, el grebo.

Ogún el tallador de los fuegos

escogió entre tótems modelo:

[Tachado: cuerpo de sierpe. A mano: serpiente,] burladora de trampas;

movimientos [Tachado: relámpagos. A mano: rápidos] de ardilla;

coraza de rinoceronte para el pecho;

potente mandíbula, garra de león.

El vaho, los sudores, la saliva

aceitan [Tachado: aceitarán] su resbalosa piel de anguila

para limar, para moler los cepos

de la dentada quijada de la Loba

que en la guarida de las bodegas

tritura la luz, la [Tachado: carne. A mano: vida] y los huesos.

Los Orichas de los ríos y [Tachado: lagunas. A mano: las ciénagas]

acordaron amasar [Tachado: su rostro con los dedos

todavía húmedo [sic] en el vientre de la madre, A mano: en el vientre de la con su rostro húmedo de los dedos, 
dibujarle las tristezas, [A mano: la sonrisa,] los deseos, [Tachado: la sonrisa]

Puso Ochú bajo [A mano: la hojarasca de sus cepas] sus párpados [Tachado: sus párpados. A mano, pero luego tachado: la cepa]

[Tachado: chispa en la hojarasca muerta,

sombría la mirada entre las cejas

para que al abrirlos

encendido el rostro cuando mira

con la asombrada lágrima de un ojo

recogiera el sonidoluz de las estrellas.

Tachado: brillante reflejo de la chispa de sus ojos

Tachado: que iluminen su rostro cuando mire

[A mano: con la asombrada lágrima de sus ojos]

\section{4}

[A mano: ¡Hijo de Jalunga el navegante bisnieto de Sessandra

escogido de los Orichas

entre la muerte y la vida

entre la ceniza y la esperanza

entre el dolor y la alegría, [A mano, pero luego tachado: la alegría y el llanto, a mano: el dolor y la [tachado:] alegría, a mano: risa]

entre la [Tachado: risa y el llanto. A mano: alegría y el llanto]

por voluntad de los Ancestros

¡Esta noche te consagro!

Semilla que mueres

semilla que renaces

puente de dos mundos te nombro,

entre la casa de los Ancestros que se queda

y la morada extraña a donde llegas.

Por voluntad de los Ancestros

esta noche te consagro!

Abre los brazos

quédate inmóvil en el ritmo

[Tachado: la vertical que une tu cabeza a los tobillos [A mano, luego tachado: en la vertical de su cuerpo 
sea el camino de Eleguá

[A mano, tachado: Elegba

encuentra Muertos]

el camino de los muertos

[A mano, pero luego tachado: puerta]

y que tus brazos abiertos

sean la vida de nuestro pueblo

en el país desconocido. ]

[A mano: que la vertical de tu cuerpo

sobre sus brazos abiertos

sea la cruz de Elegba

vida y [tachado: puerta, alma, A mano: sombra] de nuestro pueblo

en el país desconocido.]

\section{4}

La cruz, símbolo que te nombra

sera tu palabra, tu lanza y tu sombra.

Levanta la tenaza del herrero

forjada en las fraguas de Ogún

y crúzala sobre tu lanza cazadora

la poderosa lanza de agudo rostro

regalo de Ochosí.

Serán tus armas y escudos

para templar tu alma de acero

sobre cadenas y amos vencedoras.

[1]

El símbolo de Eleguá [Tachado: Hijo de Jalunga el Grebo

en la trágica tierra del exilio]

dos serpientes mordiéndose las colas

[Tachado: sobres tus hombros llevarás

hijo de Jalunga el Grebo

pastor de las revueltas tribus su consistente compañero rompiéndole los grillos y las sogas

en la trágica tierra del exilio

te consagrarán como hijo 
y mensajero.

[2]

[Hijo de Jalunga el Grebo

el símbolo de Eleguá,

dos serpientes mordiéndose las colas

sobre tus hombres llevarás

Pastor de las revueltas tribus

su combatiente compañero

rompiéndole los grillos y las sogas.

[3]

Hijo de Jalunga el Grebo

en la tiránica tierra del exilio

por voluntad de Eleba

serás su símbolo y mensajero.

Pastor de las revueltas tribus

combatiente compañero +

sus grillos y cadenas romperás.

Dos serpientes mordiéndose las colas

identificarán tu presencia vengadora.

\section{3}

\section{BANDAMA DESPIDE A LOS ARTESANOS}

(Invocación a los artesanos)

Marcháis al exilio

condenados de Changó

Solo te acompaña la sombra

la enriquecida sombra de los ancestros.

Aléjaos tranquilos

el cuerpo desnudo

sin tambores de guerra

quebrada la lanza

perdido el escudo 
y la frente descubierta.

Solo el pasado en tu memoria

la imperdible huella de los sabios.

Lleváis vacío el corazón

sin la fiebre

sin la codicia

sin la escoria del oro.

Vuestra mano alzada

el baobab del extraño

no amenaza con el yugo

ni pretendéis cambiar

sus Orichas por los tuyos.

\section{4}

Solo el recuerdo de los ríos asoleados

el recuerdo de no haber nacido esclavo.

Marcháis al exilio

lleno el pecho de temores

mordiendo la cadena el tobillo

atadas las manos diestras.

No lleváis más dioses

que la sombra amiga

la experiencia acumulada

la inseparable sombra

de los vivos y los muertos

lazo firme que amarra

que gobierna,

que enriquece

el frágil

el corto paso por la vida. 


\begin{abstract}
Alejaos tranquilos
conquistadores sin banderas

separaos de vuestros amos

vacías las manos abiertas

vigilante la memoria, imborrables los recuerdos.

En los pueblos del exilio

son vuestros únicos afanes

reencontrar la libertad perdida

prolongar la vida de los ancestros.
\end{abstract}

\title{
25
}

Así debéis entender

muntu que te alejas prisionero

futuro pasado no es muerte

sino sombra que alumbra

la experiencia inextinguible

la fuerza creadora de tu mano

en el barro

en la fragua

y en los sueños fabulados. 